\title{
Comparison of the Effects of Cytoprotective Drugs on Human Plasma Adrenocorticotropic Hormone and Cortisol Levels with Continual Stress Exposure
}

\author{
Fumihiko Katagiri, * Toru Shiga, Yuhki Sato, Shin Inoue, Hiroki Itoh, and Masaharu Takeyama \\ Department of Clinical Pharmacy, Oita University Hospital; Hasama-machi, Oita 879-5593, Japan. \\ Received May 30, 2005; accepted July 16, 2005
}

Cetraxate hydrochloride (cetraxate), ecabet sodium (ecabet), and sulpiride, which are cytoprotective drugs, have been used to treat peptic ulcers and acute or chronic gastritis. They are reported to improve mucosal blood flow in the stomach. One of the most important factors believed to cause gastric ulcers is mental and/or physiological stress. When people feel stress, the hypothalamo-pituitary-adrenal (HPA) axis is activated. Therefore, corticotropin-releasing hormone (CRH), adrenocorticotropic hormone (ACTH), and cortisol can be indicators of stress. We examined the effects of cetraxate, ecabet and sulpiride on the plasma levels of ACTH and cortisol under stress conditions by repetitive blood sampling. Venous blood samples were taken before and $20-240 \mathrm{~min}$ after a single administration of the drugs or a placebo. A single dose of ecabet caused significant suppression of increases in plasma ACTH-like immunoreactive substance (IS) levels at 90 to $120 \mathrm{~min}$ and cortisol levels at $240 \mathrm{~min}$, compared with the response to placebo. Sulpiride only suppressed increases in plasma cortisol levels at 180 to $240 \mathrm{~min}$, compared with the response to placebo. A single dose of cetraxate had no effect on plasma ACTH-IS and cortisol levels. Ecabet may have a modulatory effect on the HPA axis while sulpiride may have a partial modulatory effect on the HPA axis. These effects might be beneficial in stress-related disease.

Key words cytoprotective drug; stress; adrenocorticotropic hormone; cortisol

The pathophysiology of acid-peptic disease may be thought of as an imbalance between aggressive factors (acid, pepsin and Helicobacter pylori infection) and local mucosal defenses; the secretion of bicarbonate, mucus and prostaglandins. Although treatment most often is directed at the reduction of aggressive factors, it can be directed at strengthening mucosal defenses of the stomach and the duodenum with so-called cytoprotective agents.

Cetraxate hydrochloride (cetraxate), introduced in 1976 as an anti-ulcer drug with a mucosal protective effect, produces a dose-related increase in gastric mucosal blood flow, ${ }^{1)}$ and raises plasma calcitonin gene-related peptide and substance $\mathrm{P}$ levels, which are powerful vasoactive substances. ${ }^{2)}$ Ecabet sodium (ecabet) and sulpiride have similar effects to cetraxate; an improvement of the gastric mucosal microcirculation and acceleration of bicarbonate secretion. ${ }^{3,4)}$

Gastric mucosal injury is greatly influenced by mental and/or physiological stress. The hypothalamo-pituitaryadrenal (HPA) axis is activated when stress is present. Corticotropin-releasing hormone $(\mathrm{CRH})$ is secreted from the hypothalamus and stimulates the pituitary. From the pituitary, adrenocorticotropic hormone (ACTH), which stimulates adrenal and accelerates cortisol secretion, is secreted. ACTH and cortisol suppress the secretion of $\mathrm{CRH}$ (negative feedback) to normalize the HPA axis. Therefore, we believe that ACTH and cortisol may be indicators of stress.

ACTH is a peptide containing 39 amino acids, and ACTHlike immunoreactive substance (IS) is found in tissues other than the pituitary gland (i.e., brain, adrenal gland, gastrointestinal tract, pancreas, thyroid gland, and placenta). The secretion of ACTH is controlled by a circadian rhythm mechanism and negative feedback from plasma cortisol and neurogenic stimulation. ${ }^{5)}$ The peptide acts to secrete glucocorticoid and rises under stress. ${ }^{6}$ )

Cortisol, commonly used to indicate the level of stress, is secreted by the zona fasciculate of the adrenal cortex and its secretion is dependent on the ACTH level.

In general, venipuncture for blood sampling is thought to be a stress factor that can increase circulating ACTH and cortisol levels. ${ }^{7}$ Repetitive blood sampling places subjects under artificial stress and venipuncture as a stressor is useful for the evaluation of the pharmacological effects of drugs. ${ }^{8)}$

To determine whether cytoprotective drugs can improve HPA axis abnormalities, which might be closely related to the genesis of peptic ulcers, we investigated the effects on stress-related hormone levels (ACTH-IS and cortisol) under continual stress after administration of cetraxate, ecabet and sulpiride.

\section{MATERIALS AND METHODS}

Materials Cetraxate (Neuer capsule; Daiichi Seiyaku Co., Ltd., Tokyo, Japan), ecabet (Gastrom granules; Tanabe Seiyaku Co., Ltd., Osaka, Japan) and sulpiride (Dogmatyl capsule; Fujisawa Pharmaceuticals Co., Ltd., Osaka, Japan) were used. Lactose (Merck Hoei Co., Ltd., Osaka, Japan) was used as placebo.

Synthetic human ACTH (1-10) was purchased from Bachem (Bubendorf, Switzerland). Antiserum to human ACTH (A516/R1H) was purchased from Biogenesis (Newfields, U.K.), and the TDx Cortisol assay kit was obtained from Abbott Japan Co., Ltd. (Tokyo, Japan). All other reagents were analytical reagent grade from commercial sources.

Subject Five healthy male volunteers (nonsmokers), aged 24-31 years (median 28 years), 55-68 kg (median 62 $\mathrm{kg}$ ), participated in the study. Each subject received information on the scientific purpose of the study and gave written informed consent. The study was approved by the ethical committee of Oita Medical University. The subjects did not 
receive any other medications during the study, and fasted for $2 \mathrm{~h}$ before the study commenced and during the experiments.

Study Schedule Cetraxate at a dose of $800 \mathrm{mg}$, ecabet at a dose of $3.0 \mathrm{~g}$, sulpiride at a dose of $150 \mathrm{mg}$, or placebo was administered orally with $100 \mathrm{ml}$ of water. Each subject was administered these drugs at intervals of one month. The dose of each drug was the maximum daily dose used in clinical therapy. Venous blood samples $(10 \mathrm{ml})$ were taken from a forearm vein before and at 20, 40, 60, 90, 120, 180 and 240 min after administration (eight times). All subjects ate lunch at 11:45-12:00, and the study was carried out from 14:00 until 18:00. When blood samples were taken at intervals of $120 \mathrm{~min}$, sampling was performed at 14:00, 16:00 and 18:00 (three times) without administering a test medicine.

Enzyme Immunoassay (EIA) of ACTH-IS The blood samples were placed in chilled tubes containing 500 kallikrein inhibitor units $/ \mathrm{ml}$ of aprotinin and $1.2 \mathrm{mg} / \mathrm{ml}$ of EDTA. After centrifugation, plasma samples were diluted fivefold with $4 \%$ acetic acid ( $\mathrm{pH} \mathrm{4.0)}$ and loaded onto a $\mathrm{C} 18$ reversed-phase cartridge (Sep-Pak C18; Millipore Corp., Milford, MA, U.S.A.). After washing with 4\% acetic acid, plasma peptides were eluted with $70 \%$ acetonitrile in $0.5 \%$ acetic acid ( $\mathrm{pH} 4.0)$. Elutes were concentrated by spin-vacuum evaporation, lyophilized and stored at $-40^{\circ} \mathrm{C}$ until assayed.

EIA for ACTH-IS was performed as previously described. ${ }^{9)}$ The assay was performed by a delayed addition method. Separation of bound and free antigen was performed on an anti-rabbit IgG (55641, ICN Pharmaceuticals, Inc., Ohio, U.S.A.) coated immunoplate (Nunc-Immuno Module Maxisorp F8, InterMed, Denmark). Human ACTH (1-10) was conjugated with $\beta$-galactosidase (Boehringer Mannheim, Mannheim, Germany) by $N$-( $\varepsilon$-maleimidocaproyloxy)succimide according to the method of Kitagawa et al. ${ }^{10)}$ The concentration of ACTH-IS was expressed as ACTH (1-10), which has the biological activity of ACTH-IS. The EIA for ACTH-IS was specific and highly sensitive to detection limits of $2.0 \mathrm{fmol} / \mathrm{ml}$.

Determination of Plasma Cortisol Levels Plasma cortisol levels were measured using a fluorescence polarization immunoassay. The detection limit of cortisol was $0.64 \mu \mathrm{g} / \mathrm{dl}$. This method shows minimal cross-reactivity with endogenous steroids (11-deoxycortisol [9.9\%], corticosterone $[6.3 \%]$ and others $[<3 \%])$.

Statistical Analysis ACTH-IS levels in plasma are expressed as the mean \pm S.D. $(\mathrm{pg} / \mathrm{ml})$. Cortisol levels in plasma are expressed as the mean \pm S.D. $(\mu \mathrm{g} / \mathrm{dl})$. Comparison of mean values was made by repeated measures one-way analysis of variance. A $p$-value less than 0.05 indicated statistical significance.

\section{RESULTS}

Effects of Cetraxate, Ecabet and Sulpiride on Plasma ACTH-IS Levels The plasma ACTH-IS level-time profiles after a single oral administration of cetraxate, ecabet and sulpiride are shown in Fig. 1. The dotted line shows the lev-

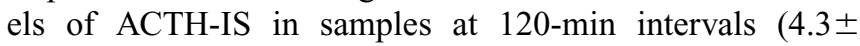
$2.0 \mathrm{pg} / \mathrm{ml}$ at $120 \mathrm{~min}$ and $5.3 \pm 2.2 \mathrm{pg} / \mathrm{ml}$ at $240 \mathrm{~min})$. At $120 \mathrm{~min}$, the ACTH-IS levels of the placebo group were significantly increased $(7.8 \pm 2.4 \mathrm{pg} / \mathrm{ml})$. The cetraxate and

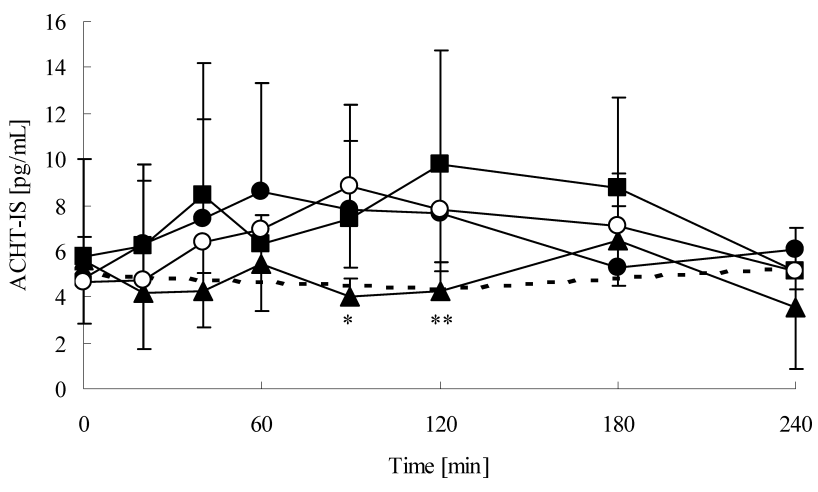

Fig. 1. Effects of Cetraxate $(\boldsymbol{O})$, Ecabet $(\mathbf{\Delta})$, Sulpiride (ם), and Placebo (O) on Plasma ACTH-IS Levels

Each value represents the mean \pm S.D. of concentrations in five volunteers. $* p<0.05$ and $* * p<0.01$, significantly different compared with placebo.

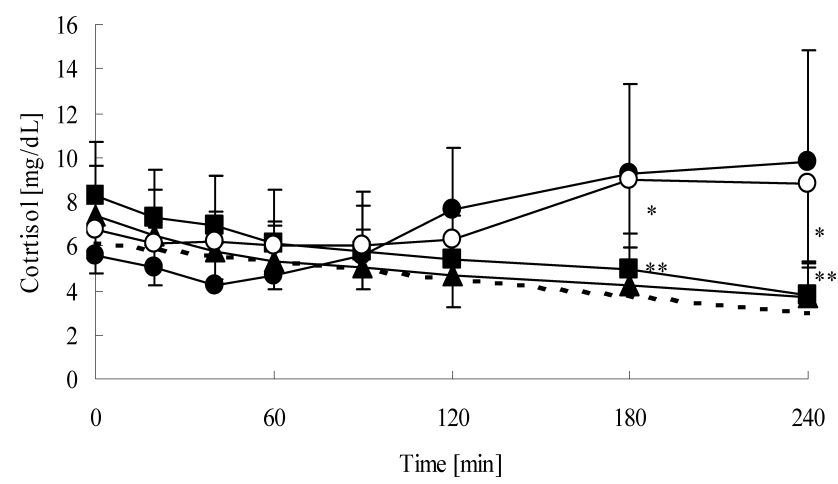

Fig. 2. Effects of Cetraxate (O), Ecabet $(\boldsymbol{\Delta})$, Sulpiride (ם), and Placebo (O) on Plasma Cortisol Levels

Each value represents the mean \pm S.D. of concentrations in five volunteers. $* p<0.05$ and $* * p<0.01$, significantly different compared with placebo.

sulpiride groups had similar profiles to the placebo group. At $120 \mathrm{~min}$, the levels of plasma ACTH-IS were also significantly increased $(7.7 \pm 1.8$ and $9.8 \pm 4.9 \mathrm{pg} / \mathrm{ml}$, respectively). Ecabet caused significant suppression of increases in ACTHIS at $90-120 \mathrm{~min}(4.0 \pm 0.8 \mathrm{pg} / \mathrm{ml}$ at $90 \mathrm{~min}$ and $4.2 \pm 1.3 \mathrm{pg} /$ $\mathrm{ml}$ at $120 \mathrm{~min})$, compared with the response of the placebo group $(8.8 \pm 3.6 \mathrm{pg} / \mathrm{ml}$ at $90 \mathrm{~min}$ and $7.8 \pm 2.4 \mathrm{pg} / \mathrm{ml}$ at $120 \mathrm{~min})$.

Effects of Cetraxate, Ecabet and Sulpiride on Plasma Cortisol Levels Figure 2 shows the plasma cortisol leveltime profiles after administration of cetraxate, ecabet and sulpiride. The dotted line shows the levels of cortisol in samples at $120-\mathrm{min}$ intervals $(4.5 \pm 1.5 \mu \mathrm{g} / \mathrm{dl}$ at $120 \mathrm{~min}$ and $2.9 \pm 0.5 \mu \mathrm{g} / \mathrm{dl}$ at $240 \mathrm{~min}$ ). The placebo group exhibited significant increases at $240 \mathrm{~min}(8.8 \pm 3.6 \mu \mathrm{g} / \mathrm{dl})$. The cetraxate group profile was not different compared to the placebo group, and showed a significant increase at $240 \mathrm{~min}(9.8 \pm$ $5.1 \mu \mathrm{g} / \mathrm{dl})$. Ecabet caused significant suppression of increases at $240 \mathrm{~min}(5.4 \pm 2.4 \mu \mathrm{g} / \mathrm{dl})$ compared with placebo group $(8.8 \pm 3.6 \mu \mathrm{g} / \mathrm{dl})$. Sulpiride also caused significant suppression of increases at $180-240 \mathrm{~min}(4.9 \pm 1.6 \mu \mathrm{g} / \mathrm{dl}$ at $180 \mathrm{~min}$ and $3.8 \pm 1.2 \mu \mathrm{g} / \mathrm{dl}$ at $240 \mathrm{~min}$ ) compared with the placebo group $(9.0 \pm 3.6 \mu \mathrm{g} / \mathrm{dl}$ at $180 \mathrm{~min}$ and $8.8 \pm 3.6 \mu \mathrm{g} / \mathrm{dl}$ at $240 \mathrm{~min})$. 


\section{DISCUSSION}

Plasma ACTH levels are regulated by two major pathways, circadian rhythm and negative feedback. Repetitive blood sampling raised ACTH-IS levels in plasma compared with sampling at intervals of $120 \mathrm{~min}$ in volunteers who received placebo. These effects of placebo on ACTH-IS are assumed to result from mental and/or physiological stress in volunteers due to repetitive blood sampling. Volunteers from whom samples were taken at intervals of $120 \mathrm{~min}$ are assumed to have been under less stress. Although cetraxate and sulpiride had no effects, ecabet suppressed the increases in ACTH-IS levels in the placebo group.

Cortisol is commonly used to indicate the level of stress. Samples taken at intervals of $120 \mathrm{~min}$ showed decreasing cortisol levels, corresponding with circadian rhythm. In general, plasma cortisol levels are high in the morning and gradually decrease from morning to afternoon. ${ }^{11)}$ Ecabet and sulpiride caused significant suppression of the increases in cortisol levels seen in the placebo group.

Ecabet had a modulatory effect on the HPA axis from the viewpoint of $\mathrm{ACTH}$ and cortisol. In this study, repetitive blood sampling resulted in increases in ACTH (120 and $180 \mathrm{~min}$ ) and cortisol (180 and $240 \mathrm{~min}$ ) levels. Changes in plasma ACTH levels were more rapid than those in cortisol, and $\mathrm{CRH}$ levels might change before the changes in $\mathrm{ACTH}$ and cortisol.

Ecabet and cetraxate are similar pharmacokinetically in that they are not transferred into the blood and have cytoprotective effects that are believed to act directly on the local gastric mucosa. It is interesting that they both have effects on the central nervous system. Direct stimulation of the gastric mucosa increased the generation of prostaglandins. The generated prostaglandins may act on the central nervous system. ${ }^{12)}$ However, the amounts of prostaglandins are produced slightly, and cannot explain the different results between cetraxate and ecabet. Although they have similar pharmacological cytoprotective effects, only ecabet has anti-urease activity. Helicobacter pylori has urease, which is an enzyme that breaks down urea in the stomach into ammonia and carbon dioxide, and the bacteria can survive in strongly acidic conditions. Ecabet has an eradicative effect on Helicobacter pylori. ${ }^{13)}$ Baričević et al ${ }^{14)}$ reported that the plasma cortisol levels of subjects infected with Helicobacter pylori were significantly higher than those of subjects not infected. It is not known how Helicobacter pylori infection is related to the HPA axis, and whether the anti-urease effect might be related to a modulatory effect on the HPA axis, however the modulatory effect is believed to be clinically useful.

Sulpiride did not have any modulatory effects on plasma ACTH-IS levels, but it did have a modulatory effect on plasma cortisol levels. Sulpiride is widely used for the treatment of depression, which is closely related to stress. ${ }^{15)}$ It is possible that the drug normalized some aspects of the stress modulatory system, such as the HPA axis. Furthermore, there are some reports that dopamine regulates the HPA axis ${ }^{16,17)}$ as well as the secretion of ACTH and cortisol. ${ }^{18)}$ The stress modulatory system is very complicated ${ }^{19)}$ and we do not know how the action of sulpiride on $\mathrm{D}_{2}$ receptor blockage influences plasma cortisol level modulation. Further detailed studies are needed.

In conclusion, although cetraxate had no effect, ecabet regulated plasma ACTH-IS and cortisol levels and sulpiride regulated plasma cortisol levels under stress conditions. It is surprising that a locally active medicine (ecabet) has modulatory effects equal to those of a drug that acts on the central nervous system (sulpiride). These modulatory effects might be beneficial in stress-related disease and the pharmacological activities of these medicines should be further investigated from basic research and clinical perspectives.

\section{REFERENCES}

1) Murakami M., Teramura S., Tamamoto K., Fujii R., Dekigai H., Yoo J. K., Saita H., Kita T., Jpn. Pharmacol. Ther, 19, 1495-1499 (1991).

2) Katagiri F., Sato Y., Itoh H., Takeyama M., J. Pharm. Pharmacol., 56, 557-561 (2004).

3) Onoda Y., Takido M., Magaribuchi T., Tamaki H., Jpn. J. Pharmacol., 52, 631-638 (1990).

4) Matsuo H., Seki A., Shinryo, 24, 958 -959 (1971).

5) Tornello S., Orti E., Alejandro F., De Nicola A., Rainbow T. C., McEwen B. S., Neuroendocrinology, 35, 411-417 (1982).

6) Harbuz M. S., Lightman S. L., J. Endocrinol., 134, 327-339 (1992).

7) Ferriani R. A., Silva de Sa M. F., Int. J. Gynaecol. Obstet., 23, 459462 (1985).

8) Vachon P., Moreau J. P., Contemp. Top. Lab. Anim. Sci., 40, 22-24 (2001).

9) Nagano T., Itoh H., Soeda F., Takeyama M., Jpn. J. Hosp. Pharm., 25, $257-263$ (1999)

10) Kitagawa T., Shimozono T., Aikawa T., Yoshida T., Nakamura H., Chem. Pharm. Bull., 29, 1130-1133 (1981).

11) Hiroshige T., Sakakura M., Ito S., Endocrinol. Jpn., 16, 465-469 (1969).

12) Gadek-Michalska A., Spyrka J., Bugajsk J., J. Physiol. Pharmacol., 56, 287-298 (2005).

13) Fukuda Y., Mizuta T., Yamamoto I., Tamura K., Shimoyama T., Scand. J. Gastroenterol., 29, 1055-1056 (1994).

14) Baričević I., Nedić O., Nikolić J. A., Bojić B., Jojić N., Clin. Biochem., 37, 997-1001 (2004).

15) Willner P., Hale A. S., Argyropoulos S., J. Affect. Disord., 86, 37-45 (2005).

16) Borowsky B., Kuhn C. M., J. Pharmacol. Exp. Ther, 256, 204-210 (1991).

17) Hagan D. M., Brooks A. N., J. Endocrinol., 151, 439-447 (1996).

18) Spencer S. J., Ebner K., Day T. A., Eur. J. Neurosci., 20, 1008-1016 (2004).

19) Al-Ayadhi L. Y., Ann. Saudi Med., 25, 36- 40 (2005). 